DISTRIBUTION STATEMENT A: Approved for public release; distribution is unlimited.

\title{
Applications of Synthetic Aperture Radar to Meteorology and Oceanography Command Operations
}

\author{
Todd D. Sikora \\ Millersville University \\ P.O. Box 1002 \\ Millersville, PA 17551-0302 \\ phone: (717) 872-3289 fax: (717) 871-4725 email: Todd.Sikora@millersville.edu \\ George S. Young \\ The Pennsylvania State University \\ 503 Walker Building \\ University Park, PA 16803 \\ phone: (814) 863-4228 fax: (814) 865-9429 email: young@meteo.psu.edu \\ Nathaniel S. Winstead \\ Johns Hopkins University Applied Physics Laboratory \\ 11100 Johns Hopkins Road \\ Laurel, MD 20723 \\ phone: (240) 228-6152 fax: (240) 228-5548 email: nathaniel.winstead@jhuapl.edu \\ Grant Numbers: N00014-06-1-0046 (Sikora) \\ N00014-07-1-0934 (Young) \\ and N0014-07-1-0577 (Winstead)
}

\section{LONG-TERM GOALS}

Our long-term goal is to employ near-surface wind speed derived from synthetic aperture radar (SAR) images of the sea surface as a marine meteorological research and forecasting tool. That is, we aim to use SAR-derived wind speed (SDWS) images to discover dynamical and morphological characteristics of microscale, mesoscale, and synoptic scale marine meteorological phenomena. We also aim to demonstrate how the fruits of our discovery can be used to aid marine meteorological analysts and forecasters.

\section{OBJECTIVES}

1. To develop software tools for portable, automated analysis of SDWS images with the objective of resolving intense mesoscale variability within those images.

2. To develop a SDWS-based system for automated verification of, and error-warning system for, mesoscale wind forecasts produced by numerical weather prediction (NWP) models. The emphasis is on verification and error detection in those regions most challenging to mesoscale numerical weather prediction models_-namely, the near-shore zones adjacent to complex topography. 


\section{Report Documentation Page}

Form Approved

OMB No. 0704-0188

Public reporting burden for the collection of information is estimated to average 1 hour per response, including the time for reviewing instructions, searching existing data sources, gathering and maintaining the data needed, and completing and reviewing the collection of information. Send comments regarding this burden estimate or any other aspect of this collection of information,

including suggestions for reducing this burden, to Washington Headquarters Services, Directorate for Information Operations and Reports, 1215 Jefferson Davis Highway, Suite 1204, Arlington

VA 22202-4302. Respondents should be aware that notwithstanding any other provision of law, no person shall be subject to a penalty for failing to comply with a collection of information if it

does not display a currently valid OMB control number.

\begin{tabular}{|c|c|c|}
\hline $\begin{array}{l}\text { 1. REPORT DATE } \\
\mathbf{2 0 0 9}\end{array}$ & 2. REPORT TYPE & $\begin{array}{l}\text { 3. DATES COVERED } \\
\mathbf{0 0 - 0 0 - 2 0 0 9} \text { to 00-00-2009 }\end{array}$ \\
\hline \multirow{3}{*}{\multicolumn{2}{|c|}{$\begin{array}{l}\text { 4. TITLE AND SUBTITLE } \\
\text { Applications Of Synthetic Aperture Radar To Meteorology And } \\
\text { Oceanography Command Operations }\end{array}$}} & 5a. CONTRACT NUMBER \\
\hline & & 5b. GRANT NUMBER \\
\hline & & 5c. PROGRAM ELEMENT NUMBER \\
\hline \multirow{3}{*}{\multicolumn{2}{|c|}{ 6. AUTHOR(S) }} & 5d. PROJECT NUMBER \\
\hline & & 5e. TASK NUMBER \\
\hline & & 5f. WORK UNIT NUMBER \\
\hline \multicolumn{2}{|c|}{$\begin{array}{l}\text { 7. PERFORMING ORGANIZATION NAME(S) AND ADDRESS(ES) } \\
\text { Millersville University,P.O. Box 1002,Millersville,PA,17551 }\end{array}$} & $\begin{array}{l}\text { 8. PERFORMING ORGANIZATION } \\
\text { REPORT NUMBER }\end{array}$ \\
\hline \multirow{2}{*}{\multicolumn{2}{|c|}{ 9. SPONSORING/MONITORING AGENCY NAME(S) AND ADDRESS(ES) }} & 10. SPONSOR/MONITOR'S ACRONYM(S) \\
\hline & & $\begin{array}{l}\text { 11. SPONSOR/MONITOR'S REPORT } \\
\text { NUMBER(S) }\end{array}$ \\
\hline
\end{tabular}

12. DISTRIBUTION/AVAILABILITY STATEMENT

Approved for public release; distribution unlimited

13. SUPPLEMENTARY NOTES

14. ABSTRACT

Our long-term goal is to employ near-surface wind speed derived from synthetic aperture radar (SAR) images of the sea surface as a marine meteorological research and forecasting tool. That is, we aim to use SAR-derived wind speed (SDWS) images to discover dynamical and morphological characteristics of microscale, mesoscale, and synoptic scale marine meteorological phenomena. We also aim to demonstrate how the fruits of our discovery can be used to aid marine meteorological analysts and forecasters.

15. SUBJECT TERMS

16. SECURITY CLASSIFICATION OF:

\begin{tabular}{c|c|c|c|c|c}
$\begin{array}{c}\text { a. REPORT } \\
\text { unclassified }\end{array}$ & $\begin{array}{c}\text { b. ABSTRACT } \\
\text { unclassified }\end{array}$ & $\begin{array}{c}\text { ABSTRACT } \\
\text { unclassified }\end{array}$ & $\begin{array}{c}\text { OF Pame as } \\
\text { Report (SAR) }\end{array}$ & $\mathbf{1 2}$ & RESPONSIBLE PERSON \\
& & &
\end{tabular}


3. To empirically and theoretically investigate the SDWS-signature of convectively-driven squall / lull couplets. The analysis includes the forcing, structure, and predictability of these intense mesoscale variations in the near-surface wind field. The goal is to make incremental gains towards improved NWP model and statistical forecasts of this phenomenon.

In the context of these objectives, we have outlined five tasks:

Task 1. To develop a highly portable, efficient, and verifiable CMOD 4/5 hybrid software system for SDWS retrieval.

Task 2. To develop a fully automated system for mapping intense mesoscale variability in SDWS images.

Task 3. To determine the forcing, structure, and predictability of the convectively-driven open ocean squall / lull couplet features frequently seen within SDWS images.

Task 4. To develop a SDWS-based system for automated verification of, and error-warning system for, mesoscale wind forecasts produced by NWP models.

Task 5. To publish results in appropriate journals and present research at relevant conferences.

\section{APPROACH}

Our approach remains essentially unchanged since last year. The basis of this research continues to be the approximately 35,000+ SDWS image frames from the Bering Sea, Gulf of Alaska, East Coast of the United States, and the North Atlantic Ocean (from 1998 to present) contained in an archive at The Johns Hopkins University Applied Physics Laboratory (JHUAPL). This data is provided at no cost by Dr. Winstead. The image archive has been used extensively by the PIs to study atmospheric phenomena in the Gulf of Alaska. In addition to previous ONR-funded research of Drs. Sikora and Young (N00014-06-10046 [Sikora] and N00014-04-10539 [Young]), Drs. Winstead and Young participated in an NSF-sponsored study of barrier jets in the Gulf of Alaska using SDWS images. During the course of these research projects, a catalog of various imaged phenomena was generated by Drs. Sikora and Young (Stepp et al. 2007). This catalog documented a number of phenomena causing intense mesoscale variations in the near shore wind field: gap flow exit jets (Figure 1), topographic gravity waves (Figure 2), and island wakes (Figure 3). In the open ocean, the most intense wind speed variability was caused by quasi-circular squall / lull couplets (Figure 4) described in Young et al. [2007] and synoptic-scale atmospheric fronts (Figure 5) described in Young et al. [2005]. The approach described here is designed to automate the quantitative description of these intense mesoscale wind variations and lay the basis for forecasting them via a combination of numerical weather prediction and statistical post-processing.

The project is organized as a series of tasks, each of which builds on the preceding results. Task 1 , the development of a highly portable, efficient, and verifiable CMOD 4/5 hybrid software system for SDWS retrieval, was completed last year and, thus, is not covered in this report. Task 2, the development of a fully automated system for mapping intense mesoscale variability in SDWS images, was completed this fiscal year with the results published this fiscal year [Young et al., 2008]. Task 3, determination of forcing, structure, and predictability of the convectively-driven open ocean squall / 
lull couplet features frequently seen within SDWS images, was completed this year with a manuscript currently under preparation for submission to Monthly Weather Review. Tasks 4 and 5 are ongoing.

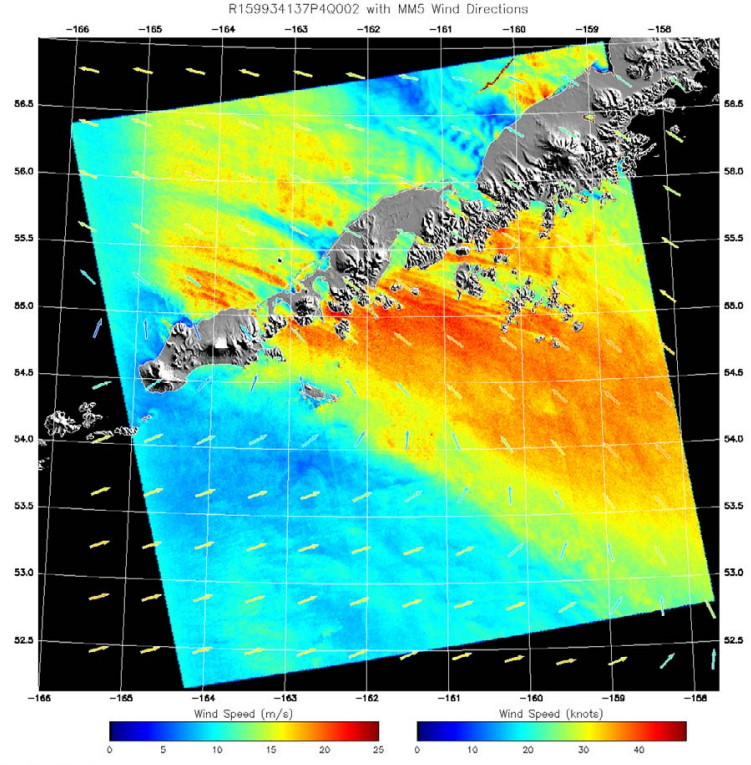

Figure 1. Radarsat-1 SDWS image depicting the signature of gap flow exit jets forced by stablystratified flow through topography ahead of a front. Terrain-driven gravity waves and island wakes are also visible. The $600 \mathrm{~m}$ pixel image is 1200 pixels by 1200 pixels. The image was acquired over the Alaska Peninsula at 0426 UTC on 29 April 2007. The near-surface wind speed varies by $20 \mathrm{~m} / \mathrm{s}$ across the front. Arrows indicate MM5 model winds. (Provided courtesy of JHUAPL)

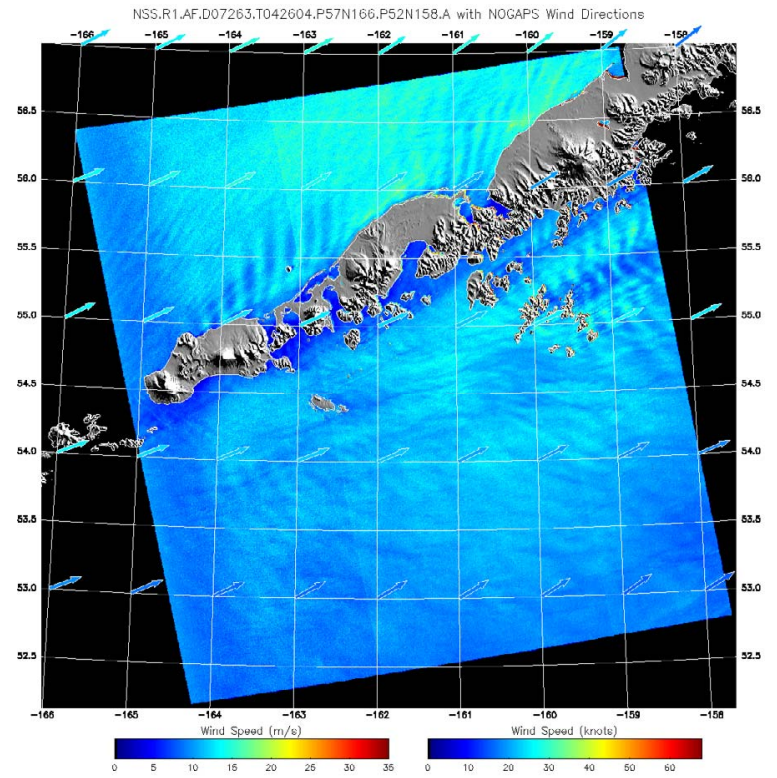

Figure 2. Radarsat-1 SDWS image depicting the signature of gravity waves forced by stably stratified flow over mountainous islands. The $600 \mathrm{~m}$ pixel image is 1200 pixels by 1200 pixels. The image was acquired off the Alaskan Peninsula at 0426 UTC on 20 September 2007. Arrows indicate NOGAPS model winds. (Provided courtesy of JHUAPL) 


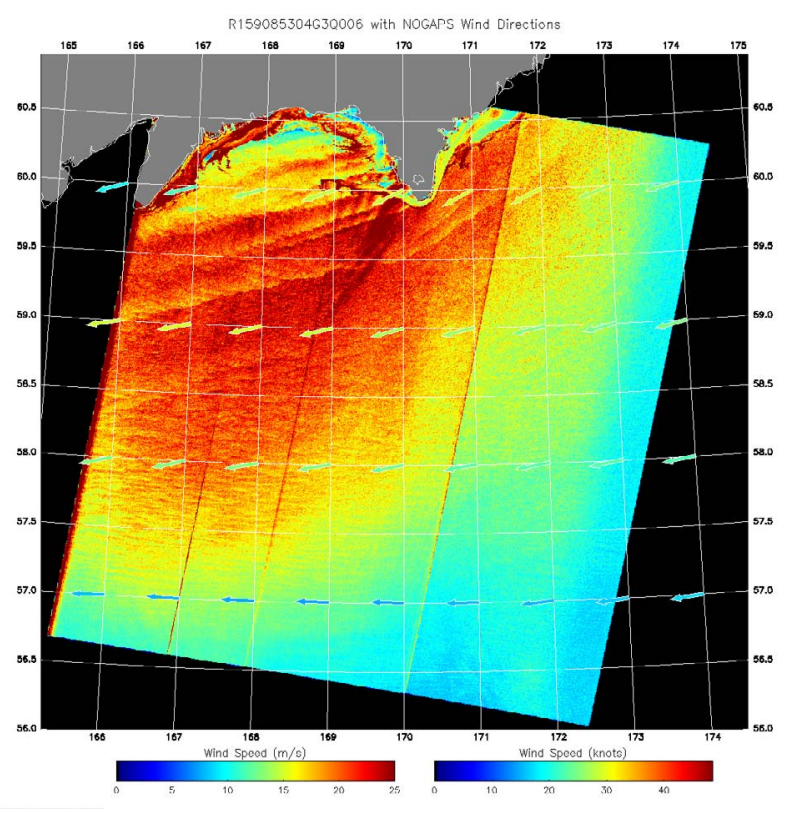

Figure 3. Radarsat-1 SDWS image depicting the signature of slow wakes forced by turbulent flow over a mountainous peninsula and the bow shocks caused by flow past the tip of the peninsula. The $600 \mathrm{~m}$ image is 1200 pixels by 1200 pixels. The image was acquired off the Siberian coast at 1833 UTC on 28 February 2008. Wind speed varies from strong breeze to storm in these terrain-driven mesoscale flows. Arrows indicate NOGAPS model winds. (Provided courtesy of JHUAPL)

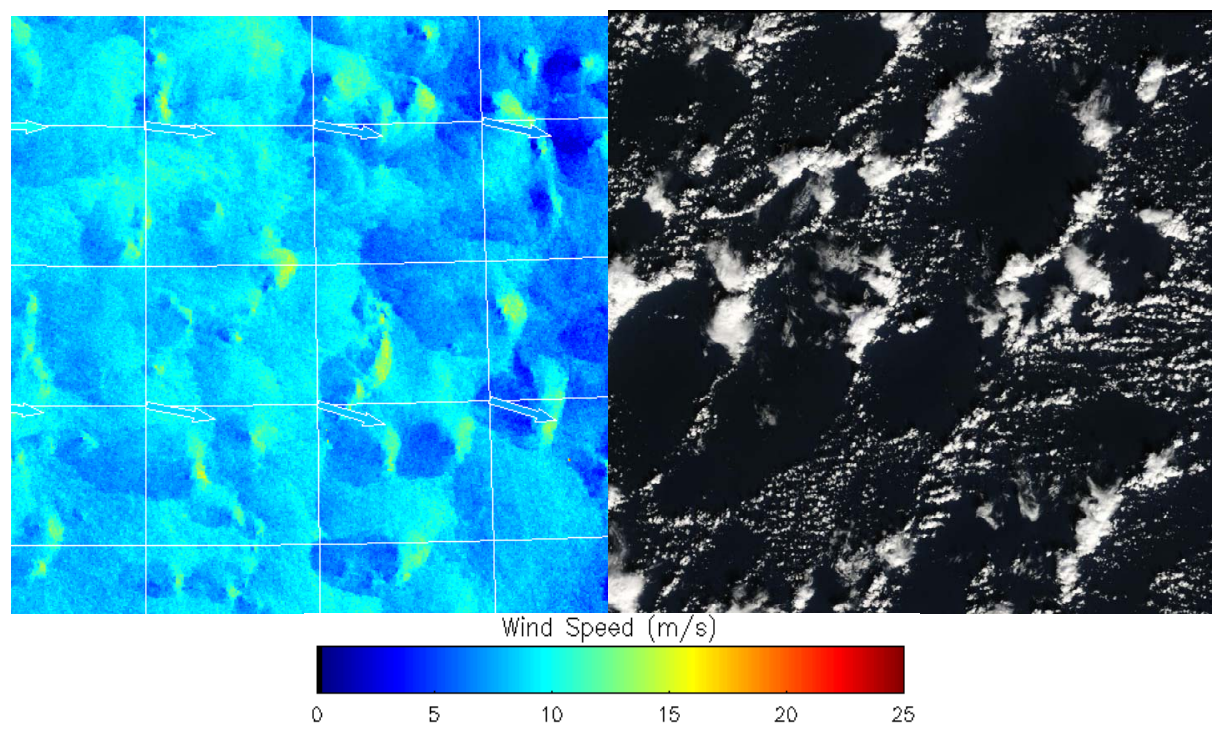

Figure 4. At left is a Radarsat-1 SDWS image depicting the quasi-circular signatures of convectively-driven open ocean squall / lull couplets. The $600 \mathrm{~m}$ pixel image is 450 pixels by 450 pixels. The image was acquired over the Gulf of Alaska at 0301 UTC on 8 November 2006. Arrows indicate NOGAPS model winds. (Provided courtesy of JHUAPL) At right is the closest corresponding MODIS image, a Terra satellite image of the region at 1955 UTC on 7 November 2006. The 250 m pixel image is 900 pixels by 900 pixels. It shows open-cell mesoscale cellular convection with a scale similar to the SDWS signatures. (Provided courtesy of NASA) 


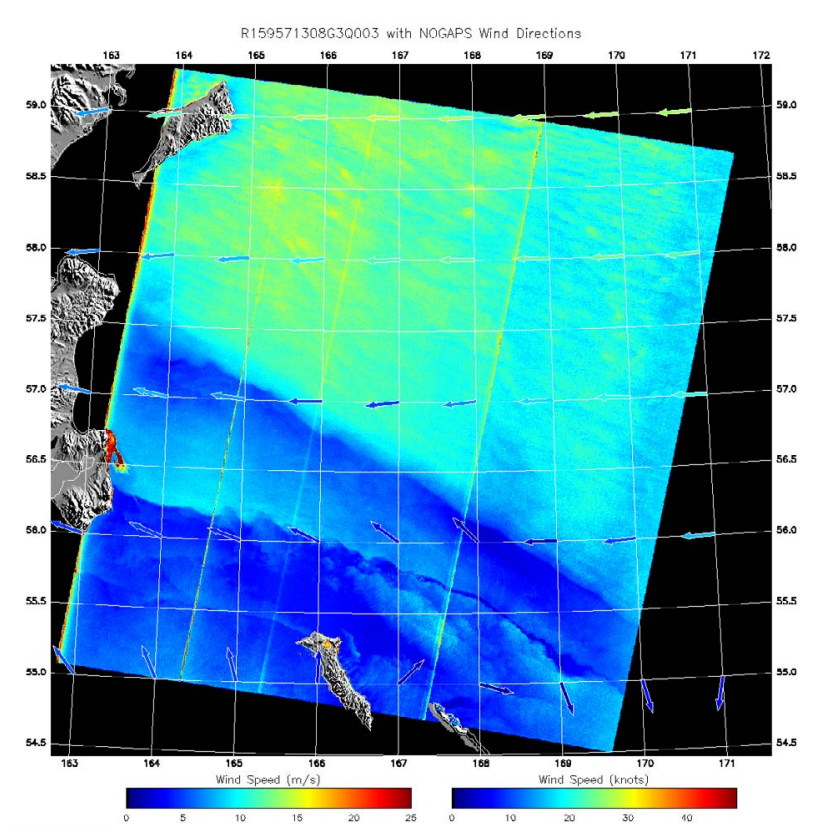

Figure 5. Radarsat-1 SDWS image depicting the near-zero-order discontinuity signatures of two synoptic-scale atmospheric fronts, both with baroclinically-driven waves. The $600 \mathrm{~m}$ pixel image is 1200 pixels by 1200 pixels. The image was acquired over the North Pacific at 1910 UTC on 3 April 2007. Arrows indicate NOGAPS model winds. Near-surface winds increase approximately $5 \mathrm{~m} / \mathrm{s}$ across each front. (Provided courtesy of JHUAPL)

The approach taken to Tasks 2 through 4 is described in the remainder of this section with the results presented in the Results section below. Task 5, the publication of results, has continued throughout the project and the resultant papers are listed in the Publications section below.

Task 2: The foundation of the SDWS analysis is the ability to distinguish sharp-edged mesoscale variability of the wind speed field from the smooth background gradient imposed by synoptic scale weather systems. This task was approached as a digital filtering problem and objective analysis problem. Namely, feature extraction (via digital filtering and wavelet analysis) and pixel aggregation (via PCA, cluster analysis and geometric analysis) techniques focused on mesoscale near-surface wind speed variability were tested. The meteorological features examined include gravity waves, convection cells, atmospheric fronts, island wakes, and gap flows.

The new work this year involved application of a wavelet-based filter bank [e.g., Gao et al., 2008] to detect edges and determine their orientation on a pixel-by-pixel basis. This work was inspired by methodological discussions at the June 2009 Spaceborne Ocean Intelligence Workshop and by urgent operational issues that Canadian Forces are actively trying to resolve. The approach taken is to create a bank of 180 Haar Wavelet filters of identical scale, each separated by 1 degree of rotation. These filters are then applied to each pixel of a SDWS image. The filter with the highest response for each pixel is noted. Two output arrays result. The first array is an image of maximum response which highlights edges irrespective of orientation and which offers a major advantage over the traditional fixed-filter-matrix techniques tested the previous year. The second is an array of edge orientations that can be used to aggregate edge pixels into curvilinear features via geometric analysis. In this analysis, 
adjacent edge pixels having similar orientation can be aggregated into a single feature, while adjacent pixels with sharply distinct orientations are placed into separate features. The result of this geometric approach to pixel aggregation is that individual edge features may curve but not kink, and that edges which meet at a sharp angle are treated as separate entities. The method thus captures two key aspects of real-world atmospheric boundaries.

Task 3: Work continued on extending Caren Fisher’s M.S. thesis research at Penn State on convectively-driven squall / lull couplets in SDWS imagery [Young et al., 2007; Sikora et al., 2009]. We examined all available satellite-borne microwave precipitation estimates for our 24 case studies to determine if these sensors provide enough resolution to detect the convective precipitation shafts which are hypothesized to play a central role in this phenomenon.

A related study was undertaken to explain the frequent existence of gravity wave signatures on SDWS imagery of gently sloped warm and occluded fronts but not for steeply sloped cold fronts [Young et al., 2005]. This work formed the basis of Dustin Swale's M.S. thesis at Penn State, which was successfully defended during the 2009 spring semester. It was hypothesized that these surface wind patterns are caused by internal gravity waves propagating on the frontal inversion, driven by vertical shear between the two air masses, and extending down to the surface for some or all of their extent. This hypothesis was tested by examining how well the classic linear model of this phenomenon matches observations. The classic Kelvin-Helmholtz velocity profile with a rigid lower boundary and a sloping interface was used to approximate a warm frontal region. This approach for solving the wave equations on a sloping interface is the dynamical equivalent to the independent column approximation used in radiative transfer calculations. Both approximations are applicable when the gradient of the propagation environment is small enough to have a negligible direct effect on the physics. In addition, a wave crest tracing procedure was developed to explain the orientation of the wave crests relative to the cross-frontal shear vector and the surface front.

Task 4: The SDWS image filtering results from Task 2 suggest a new approach to transforming SDWS imagery to the same resolution as NWP model output. This filtering algorithm was implemented this fiscal year. The resulting low-pass SDWS array is sampled at the NWP grid locations and the resulting wind speed field is subtracted from the corresponding NWP model wind speed analysis. The product is a map of model-SAR wind speed differences. These differences are due to either model wind speed errors, or model wind direction errors causing SAR wind speed errors. In either case, the product highlights shortcomings in the model wind field analysis.

\section{WORK COMPLETED}

\section{Task 1: Completed previous year.}

Task 2: A fully-automated Haar wavelet filter bank for mapping intense mesoscale boundaries in the near-surface wind field at sea has been developed. Edge orientation information provided by the filter bank supports aggregation of boundary pixels into curvilinear features and the distinguishing of intersecting features.

Task 3: Detailed observational and modeling studies focused on determining the forcing, structure, and required conditions for the convectively-driven open ocean squall / lull couplet and shear-driven frontal gravity wave signatures, frequently visible within SDWS images, have been completed. 
Task 4: SDWS image filtering advances from Task 2 were incorporated into the software for filtering SWDS fields to NWP model resolution for detection of model errors.

Task 5: See publication list below.

\section{RESULTS}

Task 1: Covered in previous report.

Task 2: We have developed a Haar wavelet filter bank for mapping intense mesoscale boundaries in the near-surface wind field at sea. Edge orientation information provided by the filter bank supports aggregation of boundary pixels into curvilinear features and the distinguishing of intersecting features. The method was tested on a synthetic dataset designed to provide maximum challenge, a circular area of increased wind speed embedded within a strong synoptic-scale gradient with turbulence-scale noise. This pattern strongly resembles the squall / lull couplets studied in Task 3. This endeavor is particularly challenging because the boundary to be detected curves continuously and because that boundary does not follow any one contour of wind speed. Results are shown in Figure 6.
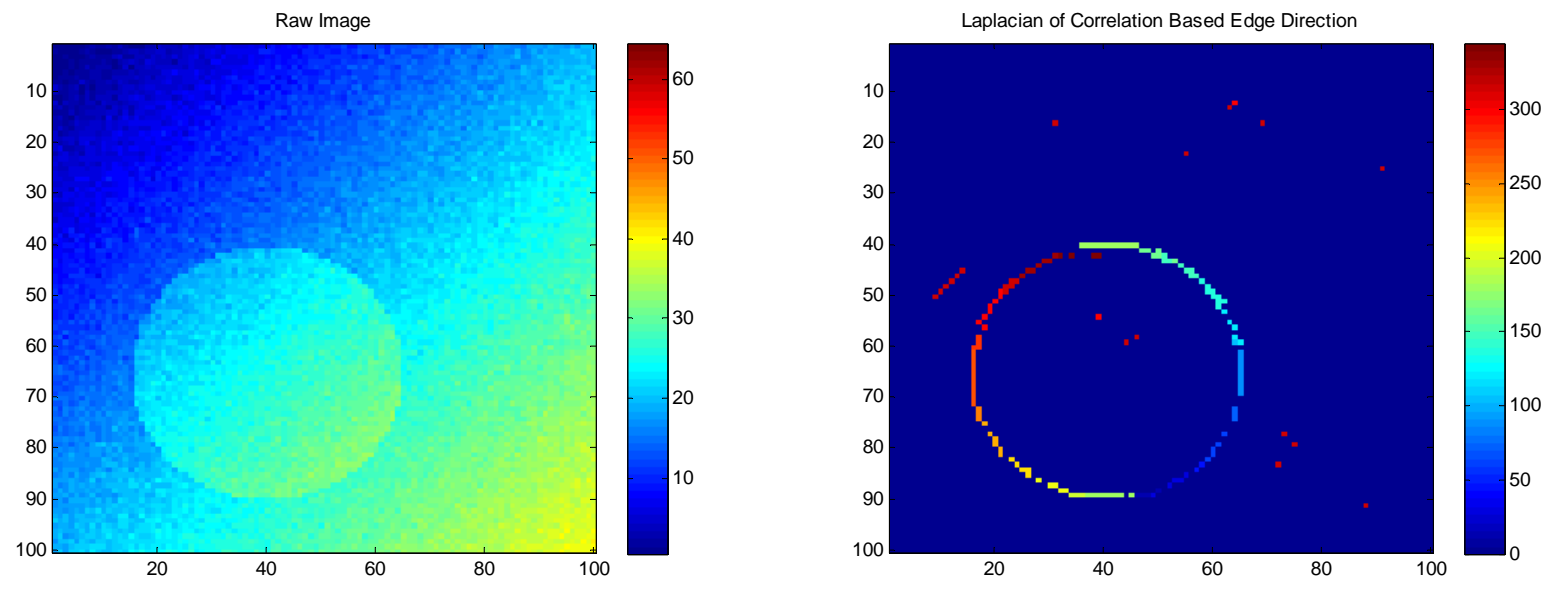

Figure 6. Haar filter bank demonstration. First image: Synthetic test image representative of the SDWS signatures of squall / Iull couplets driven by open cell convection. Second image: edge orientation for the edge pixels detected by the thresholded Laplacian of the maximum wavelet response. Note the smooth variation in the orientation and the nearly complete edge detection despite intense pixel-scale speckle in the original image.

Task 3: Examination of ASMR-3 and SSM/I F13 satellite microwave precipitation imagery did not provide a clear cut test of the hypothesized existence of convective precipitation shafts in the taller cumulus along the leading edge of the squall / lull couplets. Only spotty precipitation was detected by the microwave sensors due to their rather low spatial resolution (e.g., Figure 7). While these sensors are appropriate for stratiform precipitation and thunderstorm-type convective precipitation, they lack the spatial resolution to reliably detect precipitation from 
the towering cumulus of open cell convection which typically have diameters of only one or two kilometers.

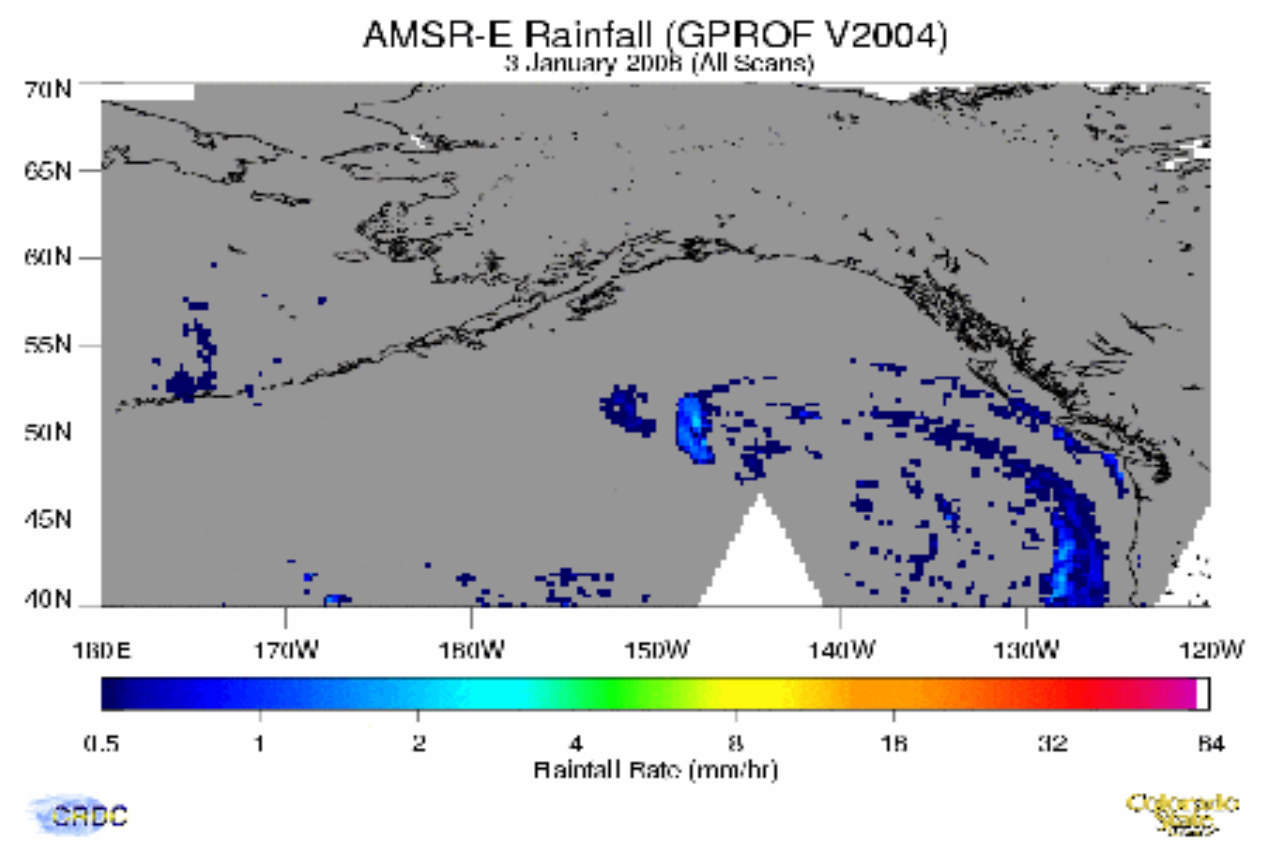

Figure 7. AMSR-E rainfall from 3 January 2006. Frontal precipitation from an occluded cyclone is captured, but only isolated returns are obtained from the open cell convection. (Provided courtesy of Colorado State University)

The frontal gravity wave study showed that the distance that the SDWS gravity wave signatures (e.g., Figure 8) extend from the surface warm front into the cool air mass is consistent with a bifurcation along the warm frontal inversion from unstable to neutral solutions of the shear-driven gravity wave equations. It was also shown that the maximum wave growth rate occurs near this bifurcation point and hence can explain the SAR-observed pattern of wind perturbation intensity wherein intensity remains nearly constant from the surface front to the end of the signatures. Ray tracing showed that the waves refract into the direction of the warm front in a manner similar to ocean swell refracting upon approaching a beach. This effect explains why the wave crests in SDWS imagery are typically aligned at an acute angle to the front, partway between the geostrophic shear vector and the frontal alignment (Figure 9). As the waves turn relative to the shear vector they achieve steady state intensity due to the decreased wave-perpendicular component of the shear. Only the growing portion of the waves is shown in Figure 9.

Task 4: Gaussian low-pass filtering was used to transform SDWS images to the resolution of operational mesoscale NWP models. A sample result is shown in Figure 10. The filtering removed the turbulence signatures and those of mesoscale island wakes too small to be resolved by such NWP models. It retained, undiminished, the synoptic scale pre-frontal jet, frontal wind speed gradient, and the resolved-scale wakes and gravity waves generated by major Alaska Peninsula volcanoes. These are the features that an operational mesoscale NWP model should be able to resolve and correctly forecast given accurate initial conditions. 
Task 5: See publication list below

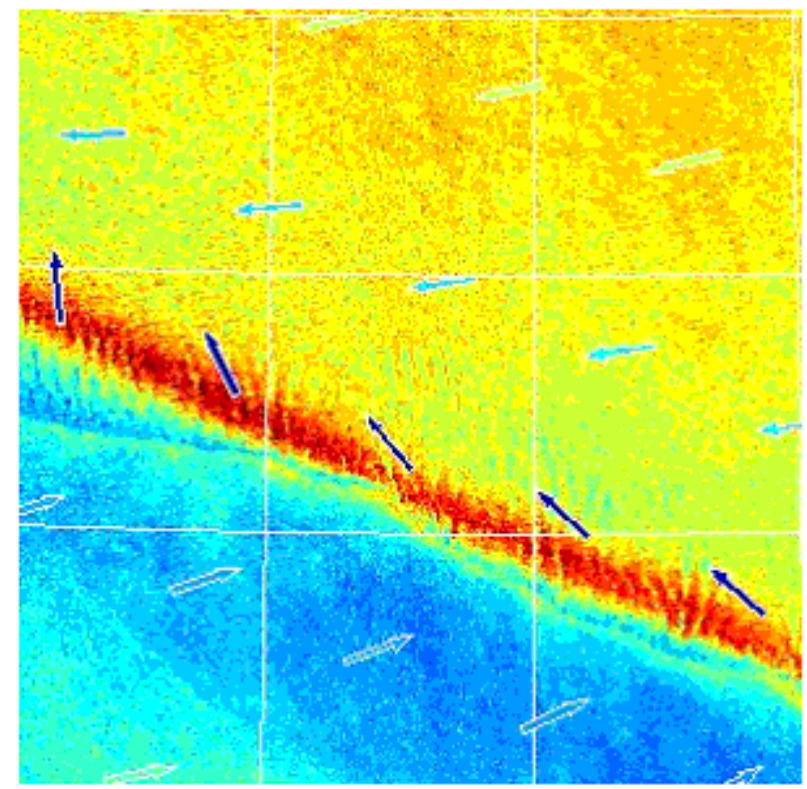

Figure 8. SDWS surface signature of warm frontal region from 28 January 2004 over the Northern Pacific Ocean. Observed wavelength is $3.67 \pm 0.6 \mathrm{~km}$. The arrows represent the surface wind direction. Arrows indicate model-derived winds. (Provided courtesy of JHUAPL)

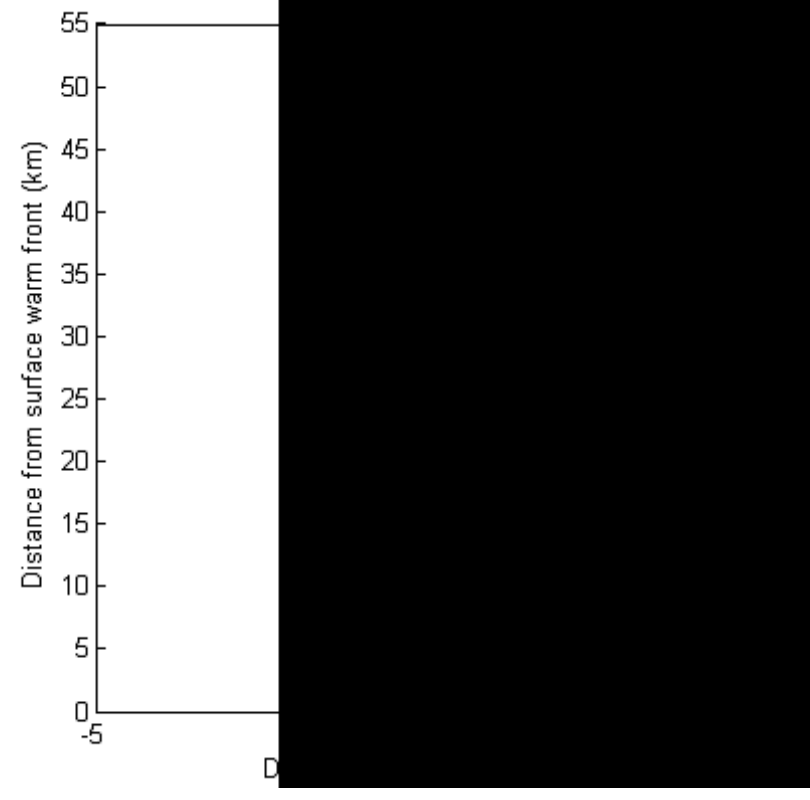

Figure 9: Propagation of wave, that which is initially perpendicular to the front (thick black line). dt $=20 \mathrm{~s}$. The lines plotted are for every 5 time steps (100s). 


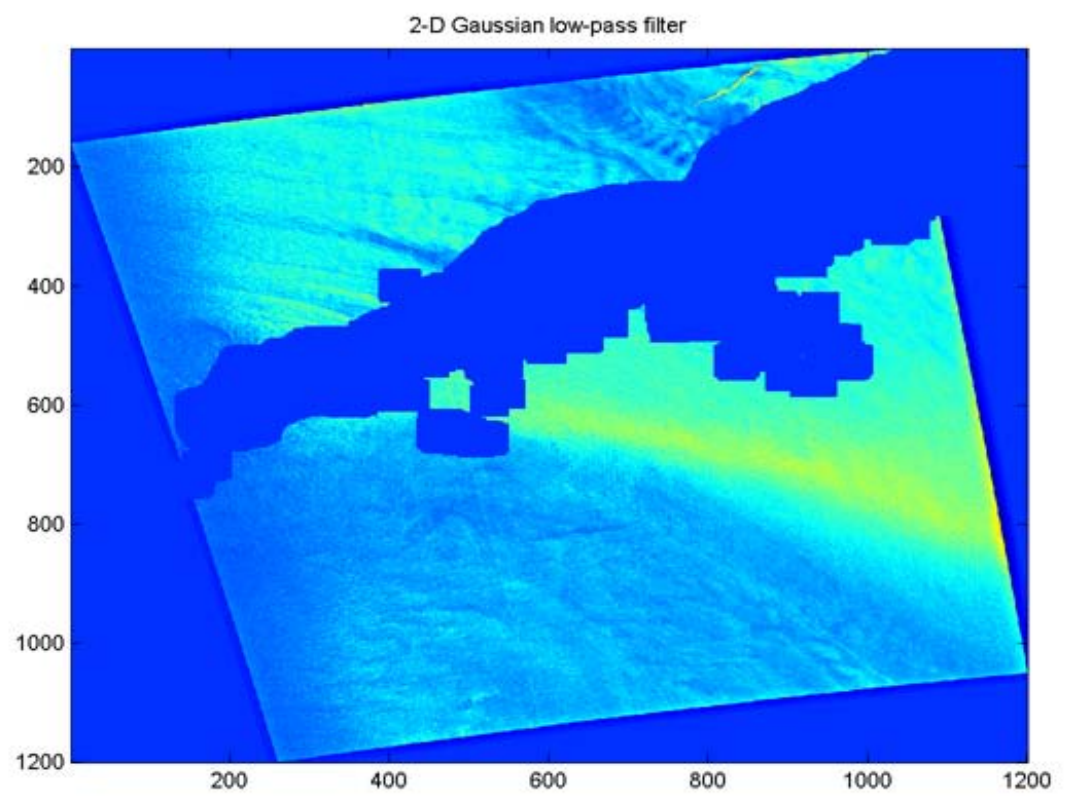

Figure 10. A low-pass filtered Radarsat-1 SDWS image with the scales that are unresolved by operational mesoscale NWP models removed. The area contaminated by land has been masked out in blue. The resulting image depicts only the mesoscale and synoptic scale components of nearsurface wind speed variability, in this case a strong pre-frontal jet passing over the Alaska Peninsula to create intense orographic gravity waves overlaid on island wakes north of the Alaska Peninsula.

The $600 \mathrm{~m}$ pixel image is 1200 pixels by 1200 pixels. The image was acquired over the Alaska Peninsula at 0426 UTC on 29 April 2007. The near-surface wind speed varies by $20 \mathrm{~m} / \mathrm{s}$ across the front. (Radarsat-1 SDWS image provided courtesy of JHUAPL)

\section{IMPACT/APPLICATIONS}

The completed research of Tasks 1 and 2 fulfill ONR objectives by working towards the automated integration of standard meteorological NWP model output and SAR data with the goal of providing high-resolution analyses of near-surface wind speed, direction, and gust intensity in in situ data-sparse regions over the ocean, including the littoral zone. Moreover, observational results associated with Task 3 will lead to improved forecasts of the same variables.

\section{TRANSITIONS}

The SAR image filtering methods developed in Task 2 were presented to Canadian Forces at the June 2009 Spaceborne Ocean Intelligence Network workshop for potential inclusion in their IAPro image analysis software. Canadian Forces were provided with Matlab code implementing these filters and edge detectors.

\section{RELATED PROJECTS}

Dr. Sikora is collaborating with Dr. Winstead and National Weather Service Weather Forecast Office Juneau meteorologists on a National Oceanic and Atmospheric Administration (NOAA)-funded 
project to study the meteorological uses of SAR for the small inlets and mountain gaps that riddle the southeast coast of Alaska. The project goal is to determine the accuracy of SDWS in gap flows under various synoptic scale situations (i.e., develop an error climatology) and to assess the impact of improved wind directions in these critical locations. This NOAA-funded project is closely aligned with Task 4.

Dr. Winstead is involved in an effort to make substantial improvements to the ANSWRS software package. During FY09, NOAA and JHUAPL finalized an agreement to re-write the ANSWRS software and wind output to meet NOAA standards for operations. Upon completion, the ANSWRS software processing stream will be declared "operational" and will be part of the NOAA data stream. One of the consequences of this change will be a standardized SAR wind data product that will meet well-defined data specifications. This standardized output wind product will be relevant for all aspects of our ONR research. The proposed ANSWERS work has passed all NOAA reviews and is awaiting contract execution. Once the final contract vehicle has been completed, work will begin immediately.

Dr. Young is part of a Penn State and NCAR team addressing the mesoscale modeling of the mesoscale wind variability caused by spatial variations in cloud cover and soil moisture. Many of the implications of this over-land work are equally applicable to the circulations driven by sea surface temperature variations. Dr. Young has focused on the fluid dynamic similarity theories for such buoyantly-driven mesoscale phenomena, including gravity currents, solenoidal circulations, and convection. Large Eddy Simulation has been used to verify the similarity theory for formation of solenoidal circulation and is in use to quantify the extent of local mixed layer similarity within such circulations, and for the phase locking of boundary layer convection by solenoidal circulations of similar horizontal scale.

\section{REFERENCES}

Gao, Q., Y. Zhao, and Y. Lu, 2008: Despeckling SAR images using stationary wavelet transform combined with directional filter banks. Applied Mathematics and Computation, 205, 517-524.

Sikora, T. D., G. S. Young, C. M. Fisher, and M. D. Stepp, 2009: Remote sensing of high-latitude open cell convection. Sixteenth Conference on Air-Sea Interaction, AMS, Phoenix, AZ, 11-15 January 2009, poster publication.

Stepp, M. D., T. D. Sikora, and G. S. Young, 2007: A climatology of marine meteorological phenomena in the Alaska region using synthetic aperture radar. Fifteenth Conference on AirSea Interaction, AMS, Portland, OR, 20-23 August 2007, poster publication.

Young, G.S., T.D. Sikora, N.S. Winstead, 2005: Use of synthetic aperture radar in fine-scale surface analysis of synoptic-scale fronts at sea. Weather and Forecasting, 20, 311-32.

Young, G.S., T.D. Sikora, and C.M. Fisher, 2007: Use of MODIS and synthetic aperture radar wind speed imagery to describe the morphology of open cell convection. Canadian J. of Remote Sens., 33, 357-367.

Young, G.S., T.D. Sikora, and N.S. Winstead, 2008: Mesoscale near-surface wind speed variability mapping with synthetic aperture radar. Sensors, 8, 7012-7034. 


\section{PUBLICATIONS}

a. Previously reported:

Fisher, C. M., G. S. Young, N. S. Winstead, and J. D. Haqq-Misra, 2008: Comparison of synthetic aperture radar-derived wind speeds with buoy wind speeds along the mountainous Alaskan coast. J. Appl. Meteorol. Clim. 471365 - 1376. [refereed]

Fisher, C. M., 2007: Remote Sensing of High Latitude Open Cell Convection [Penn State thesis]

Young, G.S., T.D. Sikora, and C.M. Fisher, 2007: Use of MODIS and synthetic aperture radar wind speed imagery to describe the morphology of open cell convection. Canadian J. of Remote Sens., 33, 357-367. [refereed]

Young, G. S., T. D. Sikora, and N. S. Winstead, 2007: Manual and semi-automated wind direction editing for use in the generation of synthetic aperture radar wind speed imagery. J. Appl. Meteor. Climatol., 46, 776-790. [refereed]

Fisher, C. M., G. S. Young, T. D. Sikora, and M. D. Stepp, 2007: Open cell convection as seen by MODIS and synthetic aperture radar. Fifteenth Conference on Air-Sea Interaction, AMS, Portland, OR, 20-23 August 2007, poster publication.

Stepp, M. D., T. D. Sikora, and G. S. Young, 2007: A climatology of marine meteorological phenomena in the Alaska region using synthetic aperture radar. Fifteenth Conference on AirSea Interaction, AMS, Portland, OR, 20-23 August 2007, poster publication.

Stepp, M. D., T. D. Sikora, and G. S. Young, 2007: Mesoscale and microscale meteorological feature climatology in the Alaska region using synthetic aperture radar. $6^{\text {th }}$ Annual AMS Student Conference, AMS, San Antonio, TX, 13-14 January 2007, poster publication.

Sikora, T. D., G. S. Young, and N. S. Winstead, 2006: Manual and semi-automated wind direction editing for use in the generation of synthetic aperture radar wind speed imagery. Proceedings, OceanSAR 2006, St. John’s, Newfoundland, Canada, 23-25 October 2006, poster publication.

b. New:

Swales, D. J., 2009: Shear driven gravity waves on a sloping front [Penn State thesis]

Sikora, T. D., G. S. Young, C. M. Fisher, and M. D. Stepp, 2009: Remote sensing of high-latitude open cell convection. Sixteenth Conference on Air-Sea Interaction, AMS, Phoenix, AZ, 11-15 January 2009, poster publication.

Young, G. S., T. D. Sikora, and N. S. Winstead, 2008: Mesoscale near-surface wind speed variability mapping with synthetic aperture radar. Sensors, 8, 7012-7034. [published, refereed] 